\title{
BREVE ANÁLISE E PROPOSTA DE INTERVENÇÃO NO BAIRRO BARTHOLOMEU BUENO DE MIRANDA - COHAB, PRESIDENTE PRUDENTE - SP
}

Jhonatam Matsuno', Thiago YugoNagai Matsutane ${ }^{1}$, Mayara Pissutti Albano², Sibila de Arêa Leão Honda $^{2}$.

Universidade do Oeste Paulista - UNOESTE, Curso de Arquitetura e Urbanismo, Presidente Prudente, SP. E-mail: sibila@unoeste.br

\section{RESUMO}

O presente artigo apresenta uma breve análise e um projeto de intervenção no bairro de habitação social Bartholomeu Bueno de Miranda, executado pela Cohabna década de 1970 em Presidente Prudente - SP. Hoje é um "sub-centro" da referida cidade, e possui vida intensa com movimentomuito grande tanto de pedestre como de automóveis, principalmente na avenida Ana Jacinta onde há comércios, residências e equipamentos urbanos. O presente trabalho tem como objetivo analisar o bairro e propor um projeto urbanístico afim de destacar a importância de uma cidade projetada para as pessoas e não para carros e maquinas, valorizando também as relações sociais locais e seus reflexos na utilização espaços públicos. A metodologia utilizada foi através de pesquisas bibliográficas buscando um aprofundamento dos assuntos trabalhados, pesquisas documentais e levantamentos in loco.

Palavras-chave: Cohab, Bairro, Intervenção, Espaços Públicos, Urbanismo.

\section{BRIEF ANALYSIS AND MOTION FOR INTERVENTION IN THE NEIGHBORHOOD BARTHOLOMEU BUENO DE MIRANDA - COHAB, PRESIDENTE PRUDENTE - SP}

\begin{abstract}
This paper presents a succinct analysis of social housing and a reform design in the social housing district called Bartholomeu Bueno de Miranda, built by Cohab in the 1970s in Presidente Prudente - SP. Nowadays, it is a "sub-center" ofthat city, and has intense urban life with strong movement of both pedestrians and cars, especially on Avenue Ana Jacinta which has trading, residences and urban services. This study has the object to analyze that district and propose a new urban design seeking to highlight the importance of the city designed for people and not for cars and machines, also enriching local social relation sand their reflections in using public spaces. The methodology used was based on literatures earching further knowledge, documentary research and survey sat spot.
\end{abstract}

Keywords: Cohab, District, Urban Design, Public Space, Urbanism. 


\section{INTRODUÇÃO}

Os bairros são lugares relativamente grandes que compõe a cidade, no qual cada um deles pode ser reconhecido por suas características, fazendo o observador se localizar com facilidade internamente e também, algumas vezes, por algumas referências externas. Elas podem ser reconhecidas e diferenciadas uma das outras por questões físicas e sociais como o espaço, forma, topografia, tipos de construção, uso, tipos de habitantes, estados de conservação, símbolo, atividades e entre outras (LYNCH, 1997).

Bezerra (2011, p. 25) afirma que:

[...] o bairro é revelado como uma forma física, um pedaço do urbano que cresce segundo tais eixos ou tais direções, e em um determinado tamanho, seu traçado segue uma lógica espaço-social. Assim, o bairro torna-se uma unidade morfológica espacial e morfológica social ao mesmo tempo.

A maneira das pessoas se localizarem facilmente pelos edifícios, espaços públicos, ruas, calçadas, significa que o local possui uma forte identidade. A preservação da característica do bairro trás uma afetividade entre a pessoa e o local onde ela circunda, como exemplo a memória afetiva, ou seja, uma pessoa ao passar em um determinado parque, tem lembranças de brincadeiras ali realizadas quando era criança, ou ao passar por uma rua, lembra da casa que morou durante a infância e boas recordações.(KOHLSDORF, 1999).

Os antigos acreditavam que existia um espírito chamado "geinus loci",o guardião da memória, ou seja, o responsável pela identidade do local. Portanto quando se pensa em intervir em uma cidade ou em um bairro é de extrema importância preservar a identidade dos espaços (KOHLSDORF, 1999).

Para se ter bairros, ou cidades em geral, mais vivos e saudáveis, deve-se proporcionar mais oportunidades de caminhar, dando mais privilégio para pessoas e não aos automóveis. Quando a pessoa circunda pelas ruas andando, nitidamente há uma percepção muito maior de seu entorno, de quando passa pelo mesmo local de carro.o incentivo ao pedestrianismo provocaria uma melhoria na questão social: as pessoas se encontrariam mais, e os espaços públicos que fazem parte dos bairros, como praças, parques, pistas de caminhada e entre outras seriam mais utilizadas (GEHL, 2013).

Diante do exposto o presente artigo tem como objetivo fazer uma breve analise de seu objeto de estudos - o bairro Bartholomeu Bueno de Miranda, localizado em Presidente Prudente SP, popularmente conhecido como COHAB. Destacando questões físicas, culturais e sociais, que 
geraram uma proposta de intervenção, afim de que o bairro tenha como prioridade as pessoas que ali residem, trabalham ou circundam.

\section{METODOLOGIA}

A metodologia adotada para o desenvolvimento do trabalho foram levantamento bibliográficos e documentais. Considerou-se também o aprendizado da disciplina Urbanismo II, ministrada no curso de Arquitetura e Urbanismo na Universidade do Oeste Paulista, no segundo semestre de 2014 e ainda realizou-se levantamentos físicos territoriais in loco.

\section{BAIRRO BARTHOLOMEU BUENO DE MIRANDA - COHAB}

Construído em 1978 na região oeste da cidade, o conjunto habitacional Bartholomeu Bueno de Miranda, possui 1017 unidades, que foram financiadas pelo BNH e construídas pela COHAB/Buru. O referido bairro, no momento de sua execução não apresentava continuidade com a malha urbana da cidade, gerando vazios urbanos (ALBANO, 2013).

Bonates (2008; p. 148) descreve os conjuntos habitacionais financiados pelo BNH, tal qual o conjunto Bartholomeu Bueno de Miranda, ressaltando a contribuição quantitativa para a minimização do déficit habitacional, no entanto, em sua maioria, "foram localizados fora da malha urbana existentes, impondo um modelo de expansão periférica para as cidades". Além de contribuir para a valorização das áreas circunvizinhas a estes conjuntos, ocasionando uma transformação "na estrutura e na paisagem urbana da maioria das cidades brasileiras", onde muitos destes conjuntos, devido às suas consideráveis dimensões, transformaram-se em bairros, como o caso de Presidente Prudente.

Atualmente, com o crescimento da malha urbana, o conjunto habitacional que se tornou um bairro importante na cidade, encontra-se inserido na malha urbana. Os bairros Jardim Bela Vista, Jardim Santa Paula, Cecap, Jardim Vale Verde e Jardim São Geraldo, são os bairros que compõem o entorno da Cohab, e são eles, bairros predominantemente residenciais.

Apenas algumas unidades habitacionais apresentam o mesmo padrão de quando foram entregues, a maioria já foi ampliada e reformada.

Kohlsdorf (1999, p. 2) afirma que:

[...] a ação perceptiva seleciona atributos do espaço físico diferentes daqueles escolhidos pelas atividades projetivas. Isto ocorre porque nessas últimas trabalha-se com representações geométricas do espaço que mostram suas dimensões de maneira muito próxima à realidade; por isso, o sistema de projeções ortogonais é o mais apropriado, mas as características que expressa (como as plantas, perfis e perspectivas 
axonométricas) não são captadas na percepção do espaço. Ele apresentase de modos diferentes, quando o percebemos e quando o consideramos através de seus predicados necessários à planificação. Mas planejadores e projetistas precisam entender as relações entre essas duas representações do espaço, para poder inferir os atributos de sua identidade que são perceptíveis e manipulá-los segundo os códigos de projetação.

Portanto, para a execução do trabalho que gerou o presente artigo, foram considerados os limites de identidade do bairro, que são diferentes daqueles encontrados nas plantas dos órgãos públicos de planejamento urbano, valorizando a importância da continuidade da identidade do local pela sua vizinhança. Para a realização deste estudo, englobou-se também a Lago dos Patos e a área onde se situa a Unidade Básica de Saúde (UBS) Praça da Juventude e Longevidade, mais conhecida como "Cohabão", que são as principais áreas livres de lazer utilizadas pelos moradores do bairro.

Os espaços públicos abertos de lazer trazem inúmeros benefícios para a melhoria da habitabilidade do ambiente urbano, dos quais pode ser citada, a possibilidade do acontecimento de práticas sociais, momentos de lazer, encontros ao ar livre e manifestações de vida urbana e comunitária, que favorecem o desenvolvimento humano (MASCARÓ e OLIVEIRA, 2007).

Tais áreas livres de lazer oferecem infraestrutura para a prática de exercícios físicos, como campos de esportes e pistas de caminhada. A Lagoa dos Patos possui arborização intensa, melhorando as condições de uso, pois quando se tem um conforto térmico às pessoas se sentem mais a vontade usar o espaço.

A Avenida Ana Jacinta é a única avenida do bairro, e possui variados comércios e equipamentos urbanos que servem tanto a Cohab, quanto bairros vizinhos. Em função da grande diversidade de produtos e serviços oferecidos, é considerado um subcentro de Presidente Prudente, conforme definições de Villaça (2001). A avenida comporta intenso fluxos de pedestres e de automóveis, pois é a principal via de acesso e distribuição de fluxos do bairro. Ela apresenta objetos de referência externa como os comércios importantes e equipamentos urbanos uma base do corpo de bombeiros, tornando-se então um marco local (LYNCH, 1997).

\section{PROPOSTA DE INTERVENÇÃO}

Através das pesquisas realizadas e dos levantamentos in loco, foi possível notar uma série de problemáticas presentes no cotidiano do bairro, como a circulação na avenida Ana Jacinta, que é bastante tumultuada em função de ser a principal via do bairro, de possuir grande quantidade de comércios e equipamentos urbanos como a escola estadual Professore Mirella Pesce Desidere, 
que possui uma grande quantidade de alunos utilizando o espaço à pé. A proposta de intervenção busca proporcionar condições melhores aos pedestres e para o espaço público, tendo como o objetivo de enfatizar que a cidade deve ter como prioridade o ser humano e sua qualidade de vida.

Outro objetivo é dar relevância à questão paisagística e o conforto dos pedestres. As pessoas que vivem e circulam pelo bairro devem se sentir bem, tanto em relação ao espaço quanto no conforto térmico, principalmente por Presidente Prudente por ter um clima quente e seco na maior parte do ano. O aumento significativo da vegetação na Cohab será de grande relevância, melhorando a sensação de bem estar dos usuários.

A relação social é outro fator importante, ou seja, favorecer a interação entre as pessoas valorizando os espaços públicos de lazer já existentes e criando novas opções de áreas de convivência.

\subsection{Proposta de Intervenção}

Para a execução da proposta de intervenção na Cohab, foram analisados projetos de intervenção em escala semelhantes, que serviram como referência projetual. As referências tinham como base a preocupação com o usuário do espaço, a convivência em espaços públicos, a prioridade ao pedestre, a inserção de vegetação como forma de melhorar aspectos sensoriais do espaço, além das análises de fluxos, setorização.

Através dos estudos realizados definiram-se as áreas de intervenção e o programa de necessidades. A Figura 1 apresenta os mapeamentos dessas áreas.

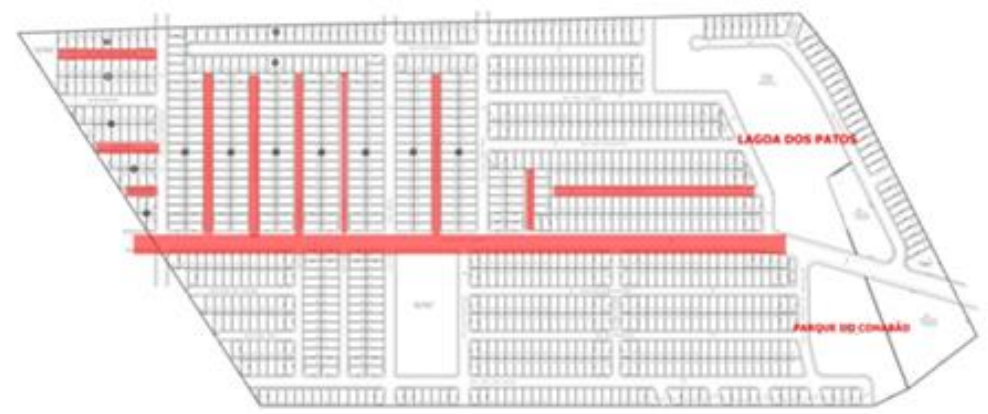

Figura 4. Área de intervenção

Fonte: Prefeitura Municipal de Presidente Prudente, modificado pelos autores, 2014.

A intervenção na Cohab - Presidente Prudente visa a priorizar o pedestres, propondo soluções que incentive a locomoção à pé, fato que não ocorre no momento; através da readequação da avenida Ana Jacinta e implantação e melhoria da vegetação arbórea no local, 
elegendo as espécies com mais capacidade de absorção de gás carbônico $\left(\mathrm{CO}^{2}\right)$. Adotar pavimentos de materiais absorventes, como o asfalto redutor de sons em vias locais, o que fará diminuir a velocidade do carro para em média $30 \mathrm{~km} / \mathrm{h}$.

Na área adjacente a Praça da Juventude e Longevidade será proposto uma estrutura permanente (Figura 5) que abrigue entre outras atividades cotidianas do bairro, a feira livre, que semanalmente ocorre na Avenida Ana Jacinta, dificultando a mobilidade no bairro. A inserção deste espaço também colaboraria para a utilização da extensa área ao lado do Posto de Saúde, que está subutilizada.

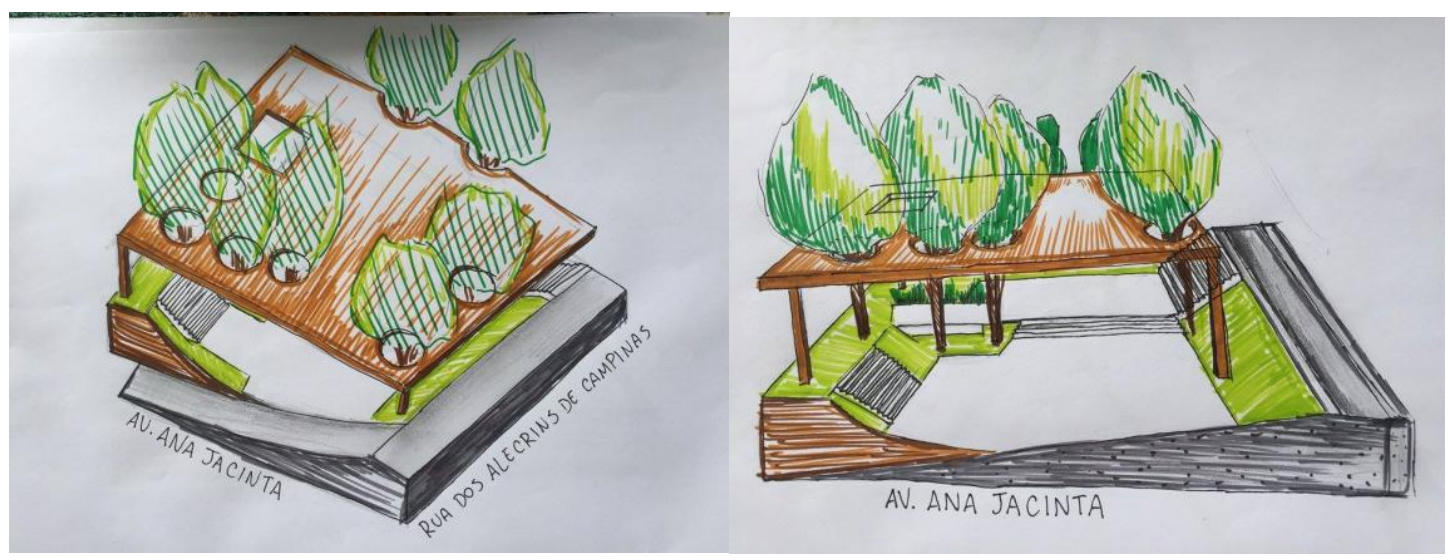

Figura 5. Croquis da proposta de intervenção na Praça da Juventude e Longevidade. Fonte: autores, 2015.

A criação do espaço para a feira livre valoriza uma cultura popular local, prioriza o tráfego de pedestres, visto que será um local onde a única forma de locomoção será à pé, e proporciona um espaço mais adequado para tal uso, através do sombreamento parcial, melhorando o conforto do usuário, o projeto consiste em um espaço amplo e coberto com uma laje de madeira com aberturas circulares para manter as árvores existentes, buscando aproveitar o máximo das condições topográficas que o terreno oferece, usando sempre os elementos de acessibilidade como escadas e rampas para proporcionar amenidade e segurança aos usuários.

Nas ruas sem saída, a proposta que se baseia no projeto de intervenção "Hibridização": a rua como extensão dos espaços privado. Busca-se, através da inserção de espaços para a participação comunitária, melhorar a relação social dos moradores e criar uma sensação de pertencimento ao local. Será proposto nos muros existentes no final das ruas sem saída jardins verticais com hortas comunitárias, à fim de que a população tome conta do espaço e tire proveito dos produtos ali produzidos. 


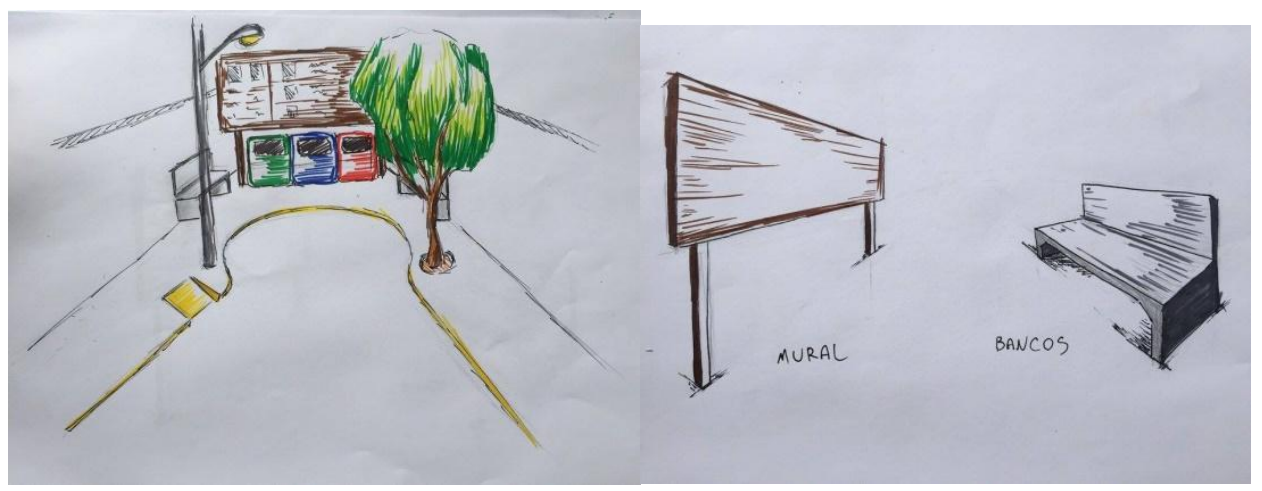

Figura 6. Croquis da intervenção

Fonte: autores, 2015.

\section{CONSIDERAÇÕES FINAIS}

O Bairro Bartholomeu Bueno de Miranda, popularmente conhecido como Cohab é um importante subcentro da cidade de Presidente Prudente. É um bairro que possui grande quantidade de comércios e serviços em sua via principal, a Avenida Ana Jacinta, e uma série de ruas sem saídas, com uso predominantemente residencial.

O presente trabalho desenvolvido na disciplina Urbanismo II do curso de Arquitetura e Urbanismo da Universidade do Oeste Paulista - UNOESTE, buscou analisar e propor melhorias para o bairro em questão. No projeto de intervenção foi dada prioridade ao pedestre e ao uso comum dos espaços públicos do bairro, como a avenida principal, as ruas sem saída e a área livre ao lado do posto de saúde adjacente ao bairro, valorizando a cultura e os costumes locais, melhorando a infraestrutura para as atividades já exercidas no local e visando a incentivar novos usos; conforme os teóricos referenciais.

\section{REFERÊNCIAS}

ALBANO, Mayara Pissutti.A importância do Planejamento urbano ambiental : a habitação social e a expansão urbana em Presidente Prudente - SP / Dissertação (mestrado).Presidente Prudente, 2013.

BEZERRA, Josué Alencar. COMO DEFINIR O BAIRRO? UMA BREVE REVISÃO/GEOTemas, Pau dos Ferros, Rio Grande do Norte, Brasil, v. 1, n. 1, p. 21-31, jan./jun., 2011.

BONATES, Maria Fialho. O Programa de Arrendamento Residencial - PAR: acesso diferenciado à moradia e à cidade. Revista de Pesquisa em Arquitetura e Urbanismo, v.7, n. 1, p. 147-164, 2008. Disponível em:http://www.arquitetura.eesc.usp.br/revista_risco/Risco7-df/02_art10_risco7.pdf. Acesso em: 8nov 2008.

GEHL, Jan. Cidades Para Pessoas. Tradução Anita Di Marco. - 1. ed. - São Paulo: Perspectiva, 2013. 
KHOLSDORF, Maria Elaine. Sobre a identidade dos lugares. In: Artigo apresentado em workshop e curso de extensão em Fortaleza, promovidos pelo IPHAN, Faculdade de Arquitetura da UFCe e Prefeitura Municipal. Brasília. 1999.

LYNCH,K.A imagem da cidade. São Paulo:Martins Fontes, 1997.

MASCARÓ, J. J. OLIVEIRA, L. A.. Análise da qualidade de vida urbana sob a ótica dos espaços públicos de lazer.Revista Ambiente Construído, Porto Alegre, v. 7, no 2, p. 59-69, abr./jun. 2007. ISSN 1678-8621.

VILLAÇA, Flávio. Espaço intra-urbano no Brasil.São Paulo: Stúdio Nobel, 2001. 